This item was submitted to Loughborough's Research Repository by the author.

Items in Figshare are protected by copyright, with all rights reserved, unless otherwise indicated.

\title{
Eating rate and food intake are reduced when a food is presented in an 'unusual' meal context
}

PLEASE CITE THE PUBLISHED VERSION

https://doi.org/10.1016/j.appet.2020.104799

PUBLISHER

Elsevier

VERSION

AM (Accepted Manuscript)

\section{PUBLISHER STATEMENT}

This paper was accepted for publication in the journal Appetite and the definitive published version is available at https://doi.org/10.1016/j.appet.2020.104799.

\section{LICENCE}

CC BY-NC-ND 4.0

\section{REPOSITORY RECORD}

McLeod, Chris, Lewis James, and Gemma Witcomb. 2020. "Eating Rate and Food Intake Are Reduced When a Food Is Presented in an 'unusual' Meal Context”. Loughborough University.

https://hdl.handle.net/2134/12631079.v1. 
1 Eating rate and food intake are reduced when a food is presented in an 'unusual' meal context

2 McLeod, C. J., James, L. J., \& Witcomb, G. L.

3

4 School of Sport, Exercise and Health Sciences, Loughborough University, Leicestershire, UK,

5 LE11 3 TU.

6

7 Corresponding author

8 Gemma L. Witcomb

9 g.1.witcomb@lboro.ac.uk

10 School of Sport, Exercise and Health Sciences

11 Loughborough University

12

13

14

15

16

17

18

19

20

21

22

23 
Abstract

25 Research has shown that 1) the slower a food is eaten the less food is consumed overall, and 2)

26 context affects portion selection. This study aimed to explore whether eating rate and food intake

27 are influenced by consuming food in 'usual' vs 'unusual' mealtime contexts. Furthermore, this

28 study aimed to identify whether mealtime-specific appropriateness and previous consumption

29 frequency corresponded with differences in eating rate and food intake between contexts.

30 Seventy-eight participants were served either cheese and tomato pasta (a typical lunch food) or

31 porridge with milk and honey (a typical breakfast food) ad libitum at both breakfast and lunch on

32 separate days. Results showed that eating rate was slower $(60.7 \mathrm{vs} 71.2 \mathrm{~g} / \mathrm{min}, p<0.001)$ and

33 less food was consumed (404.1 vs $543.2 \mathrm{~g}, p<0.001)$ when participants ate cheese and tomato

34 pasta at breakfast compared to at lunch. However, no significant differences in eating rate (54.6

35 vs $56.4 \mathrm{~g} / \mathrm{min}, p=0.75$ ) or food intake (423.7 vs $437.7 \mathrm{~g}, p=0.88$ ) were found between

36 mealtimes for porridge with milk and honey. Furthermore, differences in eating rate and food

37 intake between contexts were not associated with differences in mealtime-specific

38 appropriateness or previous consumption frequency. These results suggest that eating rate and $a d$

39 libitum food intake are influenced by the congruency of the food-to-mealtime context; however,

40 this effect is not associated with mealtime-specific appropriateness or previous consumption of

41 the food. Further research should explore the implications of introducing foods at unusual

42 mealtimes in relation to strategies for weight management.

45 Keywords: Eating rate, context, portion size, meal planning, energy intake, satiety. 


\subsection{Introduction}

Pre-meal decisions regarding portion selection have been shown to greatly influence subsequent energy intake. Approximately $90 \%$ of meals are planned in advance, not only in

49 terms of food type but also portion size, and most $(\sim 90 \%)$ are eaten in their entirety, known as

50 'plate cleaning' (Fay et al., 2011; Wilkinson et al., 2012). These pre-meal decisions are greatly

51 influenced by learned expectations about a food's sensory characteristics and its expected satiety

52 (Brunstrom, 2014; Brunstrom \& Rogers, 2009; McCrickerd \& Forde, 2016). The more often a

53 food is consumed, the more effortless pre-meal decisions become.

54 Research from our laboratory found that the influence of expected satiety (the perceived 55 satiating ability of a food) on portion size selection was mediated by the context in which these

56 decisions were made (McLeod, James, Brunstrom, \& Witcomb, 2020). That is, when foods were

57 presented at an unusual mealtime (e.g., pasta at breakfast time) smaller portions were selected to

58 stave off hunger, and expected satiety did not play as influential a role in portion selection,

59 compared to in more usual food-to-mealtime contexts (e.g., pasta at lunch time). This study

60 raised two questions about food-to-mealtime associations. Firstly, which factors determine when

61 a food is congruous or incongruous for a mealtime? We suggested that food-to-mealtime

62 associations may form through frequent consumption of a food at a specific mealtime in the past

63 (mealtime-specific previous consumption frequency) or through the perceived appropriateness of

64 consuming a food at a given mealtime, learned implicitly through social cues rather than

65 explicit food consumption. Secondly, it raised the question about whether food-to-mealtime

66 associations affect actual energy intake and other variables that impact satiety and energy intake,

67 such as eating rate. 
Previous research exploring eating rate has been extensive, as presented in a meta-

69 analysis by Robinson et al. (2014). Evidence shows that eating rate is a good predictor of food

70 intake and body mass index (Hogenkamp \& Schiöth, 2013; Leong, Madden, Gray, Waters, \&

71 Horwath, 2011; Llewellyn, Van Jaarsveld, Boniface, Carnell, \& Wardle, 2008; Robinson et al.,

72 2014). That is, individuals with slower eating rates tend to consume comparatively less food and

73 have a lower BMI than those who tend to consume their meals faster. Explicit manipulations to

74 reduce eating rate or increase chews per bite (e.g. by verbal or computerised cues; cutlery size or

75 vibrotactile feedback; food texture; or via oral device) have been shown to successfully reduce

76 energy intake while increasing satiation/satiety and decreasing the risk of later energy

77 compensation (Andrade, Kresge, Teixeira, Baptista, \& Melanson, 2012; Ferriday et al., 2016;

78 Forde, van Kuijk, Thaler, de Graaf, \& Martin, 2013; Hermans et al., 2017; James, Maher, Biddle,

79 \& Broom, 2016; Ryan et al., 2018; Scisco, Muth, Dong, \& Hoover, 2011). Previous work has

80 also shown how implicit and explicit cognitive factors can increase eating rate, such as eating

81 while distracted (Blass et al., 2006; Bolhuis, Lakemond, de Wijk, Luning, \& de Graaf, 2013),

82 eating with others (de Castro, 1990, 1994, 1995), eating large servings (Almiron-Roig et al.,

83 2015; Wilkinson et al., 2016) and eating highly palatable foods (Bobroff \& Kissileff, 1986).

84 Furthermore, Wilkinson et al. (2016) found that the perceived volume of a food portion (rather

85 than the volume of food consumed in reality) can influence eating rate. That is, eating rate was

86 faster when a portion of soup seemed small $(300 \mathrm{ml})$ but the portion that participants actually

87 consumed was larger $(500 \mathrm{ml}$; achieved by covertly replenishing the soup bowl via a peristaltic

88 pump) compared to when the portion of soup in the bowl seemed larger (500 $\mathrm{ml})$ but where less

89 soup was consumed in reality $(300 \mathrm{ml})$. This finding infers that eating rate is not influenced 
90 solely by a response to orosensory stimulation but by the perception of the portion of food 91 available.

92 Therefore, it is possible that eating rate is also influenced by other cognitive factors, such

93 as the food-to-mealtime context. Considering the eating rate literature and our previous findings,

94 we hypothesised that in incongruous food-to-mealtime contexts eating rate would be slower and

95 less food would be consumed compared to in the congruous food-to-mealtime contexts, without

96 a difference in postprandial appetite between the food-to-mealtime contexts. This is important to

97 investigate because confirming this hypothesis would present the manipulation of food-to-

98 mealtime congruency as a potential novel weight management strategy. This strategy could

99 involve the promotion of consuming liked and familiar foods at unusual mealtimes by weight

100 management practitioners as method of reducing food intake, for example. Conversely,

101 confirming this hypothesis would also indicate that larger portions are selected and eaten (at a

102 quicker eating rate) in congruous food-to-mealtime contexts which may also present a positive

103 clinical application. That is, if food products are marketed as being appropriate for a specific

104 mealtime, this may lead to more food being consumed compared to if the food was not marketed

105 meal-specifically. This strategy would be beneficial for vulnerable populations who need to

106 increase energy intake, such as the elderly or infirm.

107 Therefore, this study aimed to explore 1) the impact of food-to-mealtime congruency on

108 eating rate and food intake, and 2) the association between the difference in eating rate and food

109 intake between food-to-mealtime contexts and the measures of perceived mealtime-specific

110 appropriateness and previous consumption frequency for particular foods at particular mealtimes. 


\subsection{Methods}

\section{2.1. Overview}

114 To investigate the aims of this study, participants were recruited for a mixed design; half

115 consumed a typical breakfast food (porridge with milk and honey) and the other half a typical

116 lunch food (cheese and tomato pasta) at two mealtimes (breakfast time and lunch time) ad

117 libitum on separate days. The breakfast food consumed at breakfast time and the lunch food

118 consumed at lunch time were considered congruous food-to-mealtime contexts. The breakfast

119 food at lunch time and the lunch food at breakfast time were considered incongruous food-to-

120 mealtime contexts. At each laboratory visit, eating rate, food intake and subjective measures of

121 eating habits and food preference were recorded.

\section{2.2. Participants}

124 This study was open to males and females, aged 18 years and over. Participants were

125 recruited via opportunity sampling from and around Loughborough University, UK. Vegans and

126 vegetarians, those currently trying to lose weight, and those who did not habitually eat breakfast

127 (at least 5 days a week, defined as "the first meal of the day, consumed within 2 h of waking",

128 Clayton \& James, 2016) were excluded from the study. A screening questionnaire was also used

129 to check that potential participants were not allergic to any of the foods to be consumed as part of

130 the study, and to check that they liked ( $\geq 7$ on a 10-point Likert scale, where 10 denoted the

131 highest liking score, anchored with "Extremely") the food to be consumed. These screening

132 questions were asked for the test food (either cheese and tomato pasta or porridge with milk and

133 honey, depending on group allocation) and four dummy foods; spaghetti carbonara, Bran Flakes

134 with semi-skimmed milk, roasted vegetable and soft cheese sandwich, and toast with strawberry 
135 jam. Five foods were included to ensure participants did not know which food was being used in 136 the study.

137 Participants provided informed consent before starting the study and ethical approval was

138 obtained from the Ethics Approvals (Human Participants) Sub-Committee (Loughborough

139 University) (R18-P149).

$140 \quad$ 2.3. Test foods

141 The procedure involved asking participants to consume either a breakfast-congruous food

142 (porridge with milk and honey, referred to as 'porridge') or a lunch-congruous food (cheese and

143 tomato pasta, referred to as 'pasta') at both breakfast and lunch times. These foods were selected

144 as pilot research showed them to be commonly identifiable in the UK as regular breakfast and

145 lunch meals, respectively. See Table 1 for manufacturer details, macronutrient, energy density 146 and energy content of the test foods.

147 The participants were served the test food in an unoccupied room without distraction with 148 white crockery (for pasta) or a translucent glass bowl (for porridge) and stainless-steel cutlery.

149 Participants were offered a $250 \mathrm{ml}$ glass of water with the test food - no further water was

150 provided. The test food portion was the same for all participants in each group and was a 'double 151 portion' (i.e., larger than an average standard portion of each food) to reduce the risk of 'plate 152 cleaning' behaviour (pasta $=704-\mathrm{kcal}$ portion, porridge $=699-\mathrm{kcal}$ portion). Participants did not 153 have any information about the size of the portion. The portion was presented to the participant 154 with the knowledge that more was available. If participants consumed the initial portion to the 155 point where a refill was required (i.e., when the computer program indicated that one fifth of the 156 initial portion remained on the plate/bowl; see section 2.4.7 for further details), another double 157 portion was provided. 
159 Table 1.

160 Macronutrient, energy density and energy content of the cooked test foods (porridge with milk

161 and honey, and cheese and tomato pasta) and ingredients per $100 \mathrm{~g}$.

\begin{tabular}{clllll}
\hline Test food & $\begin{array}{l}\text { Carbohydrate } \\
(\mathrm{g})\end{array}$ & $\begin{array}{l}\text { Protein } \\
(\mathrm{g})\end{array}$ & $\begin{array}{l}\text { Fat } \\
(\mathrm{g})\end{array}$ & $\begin{array}{l}\text { Energy content } \\
(\mathrm{kcal})\end{array}$ & $\begin{array}{l}\text { Energy density } \\
(\mathrm{kcal} / \mathrm{g})\end{array}$ \\
\hline Porridge with milk and honey $^{*}$ & $\mathbf{2 0 . 7}$ & $\mathbf{5 . 2}$ & $\mathbf{3 . 2}$ & $\mathbf{1 3 5 . 6}$ & $\mathbf{1 . 3 6}$ \\
Oats $^{*}$ & 58.0 & 12.0 & 8.7 & 374.0 & 3.7 \\
Semi-skimmed milk $^{*}$ & 4.8 & 3.6 & 1.8 & 50.0 & 0.5 \\
Honey $^{*}$ & 81.5 & 0.0 & 0.0 & 329.0 & 3.3 \\
Cheese and tomato pasta $^{\text {Fusilli pasta (cooked) }}$ & $\mathbf{1 6 . 9}$ & $\mathbf{5 . 5}$ & $\mathbf{5 . 6}$ & $\mathbf{1 4 0 . 7}$ & $\mathbf{1 . 4 1}$ \\
Passata $^{*}$ & 31.6 & 5.2 & 0.86 & 176.4 & 1.8 \\
Cheddar cheese $^{*}$ & 4.4 & 1.1 & 0.5 & 28.0 & 0.3 \\
Olive oil $^{*}$ & 2.1 & 24.9 & 34.2 & 416.0 & 4.2 \\
\hline
\end{tabular}

$162 *$ Brand is Tesco.

164 2.4. Measures

165 All measures (apart from Demographic information) were presented and collected using 166 the Sussex Ingestion Pattern Monitor (SIPM) (University of Sussex, UK) computer program.

167 2.4.1. Demographic information. As part of the recruitment screening, participants

168 completed an online questionnaire asking their age, sex and how much they liked the taste of five

169 different foods (see section 2.1). Participants were also asked to complete the Three Factor

170 Eating Questionnaire (TFEQ) (Stunkard \& Messick, 1985). Height and body mass were

171 measured at the beginning of the participant's final session with BMI calculated by the

172 researcher. 
2.4.2. Appetite. Pre- and post-prandial appetite was assessed using a composite score of

174 hunger, fullness and general desire to eat (composite appetite score $=($ hunger $+(100-$ fullness $)+$

175 desire to eat) / 3) as used in previous studies (Monsivais, Perrigue, \& Drewnowski, 2007;

176 Perrigue, Drewnowski, Wang, \& Neuhouser, 2015; Perrigue, Monsivais, \& Drewnowski, 2009).

177 Each measure was presented on a 100-mm visual-analogue rating scale (VAS). Participants were

178 asked: "How hungry do you feel right now?" "How full do you feel right now?" and "How

179 strong is your desire to eat right now?" The scales were anchored with "Not at all" (0 mm) and

180 "Extremely" (100 mm).

181 2.4.3 Liking and desire to eat. Participants indicated their liking and desire to eat the

182 test foods at each mealtime using a 100-mm VAS. The liking VAS was headed: "How much do

183 you like the taste of the food in front of you in general?" and was anchored with "I hate it" $(0$

$184 \mathrm{~mm})$ and "I love it" (100 mm). Liking was measured before participants consumed the food. The

185 desire to eat scale was headed: "How much do you want to eat this food right now?" and was

186 asked after food had been presented, but before consumption. The VAS was anchored with "Not

187 at all" (0 mm) and "Extremely" (100 mm).

188 2.4.4 Mealtime-specific previous consumption frequency. Participants indicated the

189 frequency that they had previously consumed the test food at breakfast time or lunch time

190 (depending on the trial). The question was headed: "At breakfast time/lunch time, I consume

191 porridge with milk and honey/cheese and tomato pasta [n] times per..." with participants

192 indicating their response per day, week, month or year (whichever was most appropriate).

2.4.5 Mealtime-specific appropriateness. Participants indicated how appropriate they

194 believed the test food to be for each mealtime using a 100-mm VAS headed "How appropriate do 
195 you think this food is to consume at this mealtime?". The scale was anchored with "Not at all 196 appropriate" (0 mm) and "Completely appropriate" (100 mm).

2.4.6 Postprandial meal enjoyment. Participants indicated how much they enjoyed

198 consuming the test food at the end of the meal using a 100-mm VAS headed: "How much did 199 you enjoy consuming this food at this mealtime?" The scale was anchored with: "Not at all" (0 $200 \mathrm{~mm})$ and "Extremely" (100 mm).

2.4.7. Eating rate and food intake. Eating rate was assessed through continuous

202 measurements of plate/bowl mass (g) across the meal. A Sartorius Cubis MSU5201S series scale 203 was connected via USB to a PC. Both the scale and the PC were placed on a table in front of the 204 participant; however, the scale was concealed within a tailormade table with a place mat 205 positioned on top to hide the scale. During the meal, software written on the SIPM recorded the 206 mass of the plate/bowl (g) at one second intervals. The reduction of scale mass throughout the 207 eating session from food consumption was inverted to create cumulative intake data (a change in 208 scale mass of $<1 \mathrm{~g}$ was not considered a reduction in food from the plate/bowl). The computer 209 program notified the researcher and participant via an alarm that one fifth of the initial portion 210 remained on the plate/bowl. At this point, the researcher refilled the plate/bowl in a separate

211 room in $<60 \mathrm{~s}$ before presenting a full portion to the participant once more. The measurement of 212 meal duration, recorded by the SIPM, did not stop for the refill interlude. Thus, after piloting, a 213 standardised $10 \mathrm{~s}$ interval was decided upon to replace the duration of the refill interlude for all 214 participants who reached the refill stage. The final time point (and the end of the eating session) 215 was taken at the time point (s) of the last reduction of the scale mass $>1 \mathrm{~g}$. Overall meal duration 216 was adjusted accordingly if the portion consumed included a refill interval. 
Food intake was calculated by subtracting the mass of the test food at the end of the meal

218 (g) from the mass of the test food at the beginning of the meal $(\mathrm{g})$, minus the mass of the

219 plate/bowl (g). Total mouthfuls per meal were calculated by coding the number of changes $(>1 \mathrm{~g})$

220 in cumulative food intake across the eating duration. Average mouthful size $(\mathrm{g})$ was calculated by

221 dividing food intake (g) by the number of mouthfuls per meal.

\section{2.5. Procedure}

223 Participants who expressed an interest in participating in the study were sent a link to an

224 online information pack presented using the Online Survey platform (onlinesurveys.ac.uk). From

225 here, participants read the information sheet and provided informed consent by ticking a box on

226 the online form. Subsequently, participants completed the demographic questionnaire, TFEQ,

227 baseline liking scale and indicated whether they had allergies or intolerances to the ingredients of

228 the test foods. After completing the online questionnaire, eligible participants were contacted by

229 the researcher to organise times for their breakfast and lunch trials.

230 Participants were asked to take part in two trials: breakfast (0800) and lunch (1200) on

231 separate days (1-7 days apart) completed in a random, counter-balanced order. No familiarisation

232 trial was conducted. To ensure hunger was controlled, participants were asked to refrain from

233 eating for $12 \mathrm{~h}$ prior to the breakfast trial and for $3 \mathrm{~h}$ prior to the lunch trial, to avoid caffeine 12

$234 \mathrm{~h}$ prior to each trial to avoid anorexigenic effects (Schubert et al., 2017), and to refrain from

235 exercise for $24 \mathrm{~h}$ before experimental trials and for the day of the experimental trials. On each

236 occasion, after entering the laboratory, participants were asked to rate their appetite (hunger,

237 fullness and general desire to eat). On the participants' final session only, height and weight were

238 then measured by the researcher. They were then presented with five sealed envelopes. The

239 participants were told: "A different food is contained within each envelope. Please select an 
240 envelope. The food in the envelope you choose will be the meal you are allocated for your

241 breakfast/lunch today." In reality, each envelope had the test food enclosed. Once the food had

242 been selected, the researcher prepared the test food in a separate room. This covert strategy

243 occurred in all trials. Once the participant was presented with the food (but before the eating

244 session began) participants were asked to rate their liking, desire to eat, mealtime-specific

245 previous consumption frequency, and mealtime-specific appropriateness for the test food in front

246 of them. After completing these measures, the researcher said: "You have 30 minutes or less to

247 consume as much or as little food as you would like, knowing that you will not be able to eat for

2483 hours after you've finished your meal. Please don't move the plate/bowl or place your cutlery

249 on it. There is more food available than the portion you see in front of you but you don't have to

250 worry about letting me know if you would like more as an alarm will sound on the computer once

251 you have consumed a certain amount. At that point, I will enter and replenish your portion for

252 you. Once you have finished, please press the 'meal finished'button on the computer screen and

253 I will be alerted to come in." The instructions were presented on the computer screen during the

254 eating session as a reminder. The eating session then began without distraction, with eating rate

255 recorded covertly (detailed in section 2.4.7). After participants had consumed the meal (with or

256 without refills) to their satisfaction, the researcher asked the participant to rate their appetite and

257 postprandial meal enjoyment. After the final trial, the researcher asked if the participant knew the

258 intention of the research before debriefing them on the protocol. No participants guessed that

259 eating rate was being measured or that there was the intention to create incongruous food-to-

260 mealtime contexts. However, two participants guessed that food intake was being recorded. 


\subsection{Data analysis}

All data were analysed using SPSS V24 software (SPSS Inc.). Significance was accepted

263 at $p<0.05$. All data are presented as average scores with standard deviation (SD) unless

264 otherwise stated. The Greenhouse-Geisser correction was applied to adjust the degrees of

265 freedom where sphericity had been violated. Effect sizes were presented as $r$-values, as data were

266 parametric and non-parametric, which were calculated from $F$-, $Z$ - and $t$-values using equations

267 by Rosenthal (1994); benchmarks were demarcated as small if $r=|0.1|$, medium if $r=|0.3|$ and

268 large if $r=|0.5|$ (Cohen, 1992).

269 Between-group differences in participant characteristics were assessed via one-way

270 ANOVAs. A MANOVA was conducted to analyse the main effect and interaction terms for

271 eating rate, food intake, eating duration, total mouthfuls and average mouthful size. Univariate

272 analysis of each variable further investigated the significant MANOVA interaction. Two

273 (mealtimes) by two (food groups) ANOVAs were conducted to analyse main effect and

274 interaction terms for pre- and post-meal composite appetite scores, liking, desire to eat,

275 mealtime-specific appropriateness and previous consumption frequency scores, and postprandial

276 meal enjoyment scores. Significant interactions were explored by conducting two planned post

277 hoc paired-samples $t$-tests to explore the difference in scores between breakfast time and lunch

278 time for pasta and porridge, respectively. As multiple comparisons were conducted, the increased

279 likelihood of Type 1 error was addressed by applying a Bonferroni correction at each level of

280 analysis. All $p$-values are presented with the Bonferroni correction applied.

281 Eating rate was divided into quartiles in order to investigate whether changes in eating

282 rate occurred during the course of each participant's meal duration or whether eating rate was

283 consistently higher, lower or the same throughout the meal, in different food-to-mealtime 
284 contexts (Almiron-Roig et al., 2015; Westerterp-Plantenga, 2000). Four eating rate per quartile

285 scores were calculated for each of the four food-to-mealtime contexts. Subsequently, two

286 separate 2 (mealtime) by 4 (quartile) ANOVAs were conducted (one for pasta, one for porridge)

287 to assess the difference in eating rate quartiles between mealtimes.

288 Correlation analysis was used to explore the association between eating rate, food intake,

289 mealtime-specific previous consumption frequency, mealtime-specific appropriateness, desire to

290 eat, and postprandial meal enjoyment. This was conducted to analyse correlations within 1)

291 congruous contexts, 2) incongruous contexts, and 3) for change scores, i.e., differences (per

292 participant) in eating rate and food intake (respectively) between congruous and incongruous

293 contexts. Change scores were calculated as the square of the difference (incongruous context

294 score minus congruous context score, squared $\left[(\mathrm{INC}-\mathrm{C})^{2}\right]$. This analysis combined the data from

295 both the pasta and porridge groups. Shapiro-Wilk tests indicated that data for several variables

296 were not normally distributed $\left(W_{(78)}=[0.41,0.98], p=[<0.001,0.19]\right)$; thus a non-parametric

297 Kendall's tau assay was used to explore these correspondences.

\subsection{Results}

\section{$300 \quad$ 3.1. Participant characteristics}

301 Each group $(\mathrm{n}=39)$ consisted of 18 males and 21 females with an overall mean age of

$30226.0 \pm 11.4$ years. One additional participant in the cheese and tomato pasta group was excluded

303 prior to the analysis as it was clear that they did not like the pasta. Mean participant BMI and

304 TFEQ scores for restraint, disinhibition and hunger were within the normal range (Stunkard \&

305 Messick, 1985; see Table 2 for further demographic information). 
Table 2.

308 Participant characteristics $(n=78)$ for Group $1(n=39$; pasta $)$ and Group $2(n=39$; porridge $)$

309 and the results of the between-groups ANOVAs.

\begin{tabular}{lllll}
\hline & \multicolumn{3}{c}{ Mean scores $( \pm \mathrm{SD})$} & \\
\cline { 2 - 5 } Participant characteristic & Group 1 (pasta) & Group 2 (porridge) & $F$ & $p$ \\
\hline Age $(\mathrm{yr})$ & $24.8(9.0)$ & $27.1(13.7)$ & 0.77 & 0.38 \\
Height $(\mathrm{cm})$ & $172.2(9.5)$ & $172.3(8.1)$ & 0.01 & 0.93 \\
Weight $(\mathrm{kg})$ & $69.7(12.2)$ & $69.4(11.0)$ & 0.02 & 0.89 \\
BMI $\left(\mathrm{kg} / \mathrm{m}^{2}\right)$ & $23.5(3.6)$ & $23.3(2.7)$ & 0.10 & 0.75 \\
TFEQ-Restraint & $7.8(5.3)$ & $7.8(4.0)$ & 0.002 & 0.96 \\
TFEQ-Disinhibition & $6.9(3.6)$ & $6.0(3.3)$ & 1.26 & 0.27 \\
TFEQ-Hunger & $5.9(3.2)$ & $6.1(3.3)$ & 0.06 & 0.81 \\
& & & &
\end{tabular}

$310 \quad$ Note: all $\mathrm{df}_{\text {effect }}=1$, all $\mathrm{df}_{\text {error }}=77$.

\subsection{Pre-meal appetite and liking}

313 For pre-meal appetite, there was no significant effect of food group $\left(F_{(1,76)}<0.001, p=\right.$

$3140.99, r<|0.01|)$, or mealtime $\left(F_{(1,76)}=0.777, p=0.38, r=|0.10|\right)$ and there was a non-significant

315 mealtime-by-food group interaction $\left(F_{(1,76)}=0.191, p=0.66, r=|0.05|\right)$. This indicated that

316 average pre-meal composite appetite scores did not differ significantly between mealtimes for

317 the pasta group (breakfast time $=72.9 \pm 14.3 \mathrm{~mm}$; lunch time $=71.9 \pm 17.8 \mathrm{~mm}$ ), the porridge

318 group (breakfast time $=73.9 \pm 19.4 \mathrm{~mm}$; lunch time $=70.8 \pm 17.3 \mathrm{~mm}$ ) or between groups.

319 For subjective liking scores, there were no significant effects of mealtime $\left(F_{(1,76)}=0.24 p\right.$

$320=0.63, r=|0.06|)$ or food group $\left(F_{(1,76)}=2.00, p=0.16, r=|0.16|\right)$, and no significant mealtime-

321 by-food-group interaction $\left(F_{(1,76)}=0.14, p=0.71, r=|0.04|\right)$. These results indicated that

322 participants' subjective liking scores did not differ significantly between mealtimes or food

323 groups (pasta group: breakfast time $=81.8 \pm 14.3 \mathrm{~mm}$, lunch time $=81.6 \pm 14.0 \mathrm{~mm}$; porridge

324 group: breakfast time $=77.9 \pm 17.0 \mathrm{~mm}$, lunch time $=76.6 \pm 16.1 \mathrm{~mm})$. 


\subsection{Eating rate, food intake, eating duration, total and average mouthfuls per meal}

327 and average mouthfuls per meal) revealed a significant mealtime-by-food-group interaction

$328\left(F_{(5,72)}=4.07, p=0.003\right.$, Pillai's trace $\left.=0.22, r=|0.47|\right)$, a significant effect of mealtime $\left(F_{(5,72)}\right.$

$329=6.38, p<0.005$, Pillai's trace $=0.31, r=|0.55|)$ and a non-significant effect of food group

$330\left(F_{(5,72)}=1.49, p=0.20\right.$, Pillai's trace $\left.=0.09, r=|0.31|\right)$. Univariate analysis explored the

331 significant interaction term further (see Table 3 for full univariate analysis results).

332 For eating rate, there was a significant effect of mealtime $(p<0.001)$ and a mealtime-by-

333 food-group interaction $(p=0.01)$ but no effect of food group $(p=0.09)$. Post hoc analysis

334 indicated that eating rate increased significantly from breakfast time to lunch time for pasta $\left(t_{(38)}\right.$

$335=-4.23, p<0.001, r=|0.57|)$ but did not increase significantly for porridge $\left(t_{(38)}=-0.90, p=\right.$

$3360.75, r=|0.14|)($ see Figure 1).

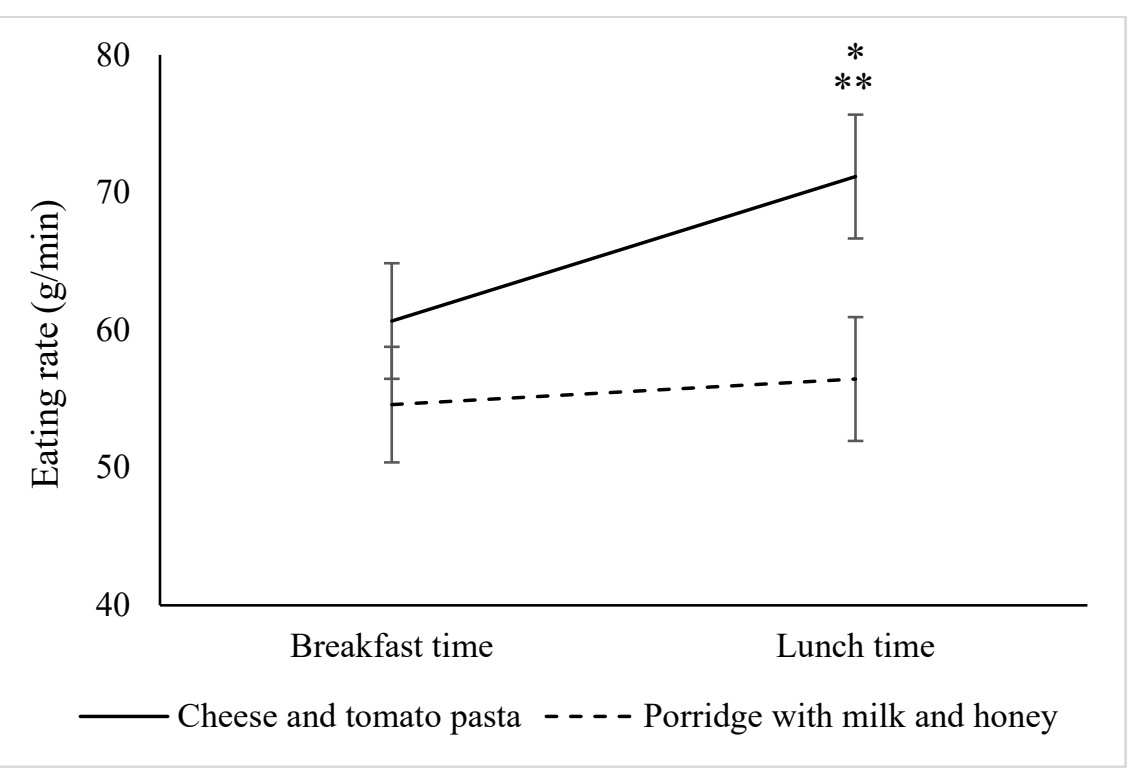

339 Figure 1. Mean $( \pm \mathrm{SEM})$ eating rate $(\mathrm{g} / \mathrm{min})$ for cheese and tomato pasta and porridge with milk and honey at breakfast time and lunch time. 
$341 *$ Eating rate was higher at lunch time compared to breakfast time $(p<0.001)$.

$342 * *$ Eating rate increased significantly from breakfast time to lunch time for the pasta group ( $p<$

$3430.001)$ but did not differ significantly for the porridge group $(p=0.75)$.

Furthermore, when eating rate was analysed per quartile for pasta and porridge,

346 respectively, the non-significant interactions indicated that changes in eating rate per quartile

347 throughout the meal were not significantly different between mealtimes for either food (pasta:

$348 F_{(2.51,95.38)}=0.21, p=0.86, r=|0.08|$; porridge: $\left.F_{(1.82,69.12)}=0.08, p=0.91, r=|0.04|\right)$. See Figure

3492 for further details.

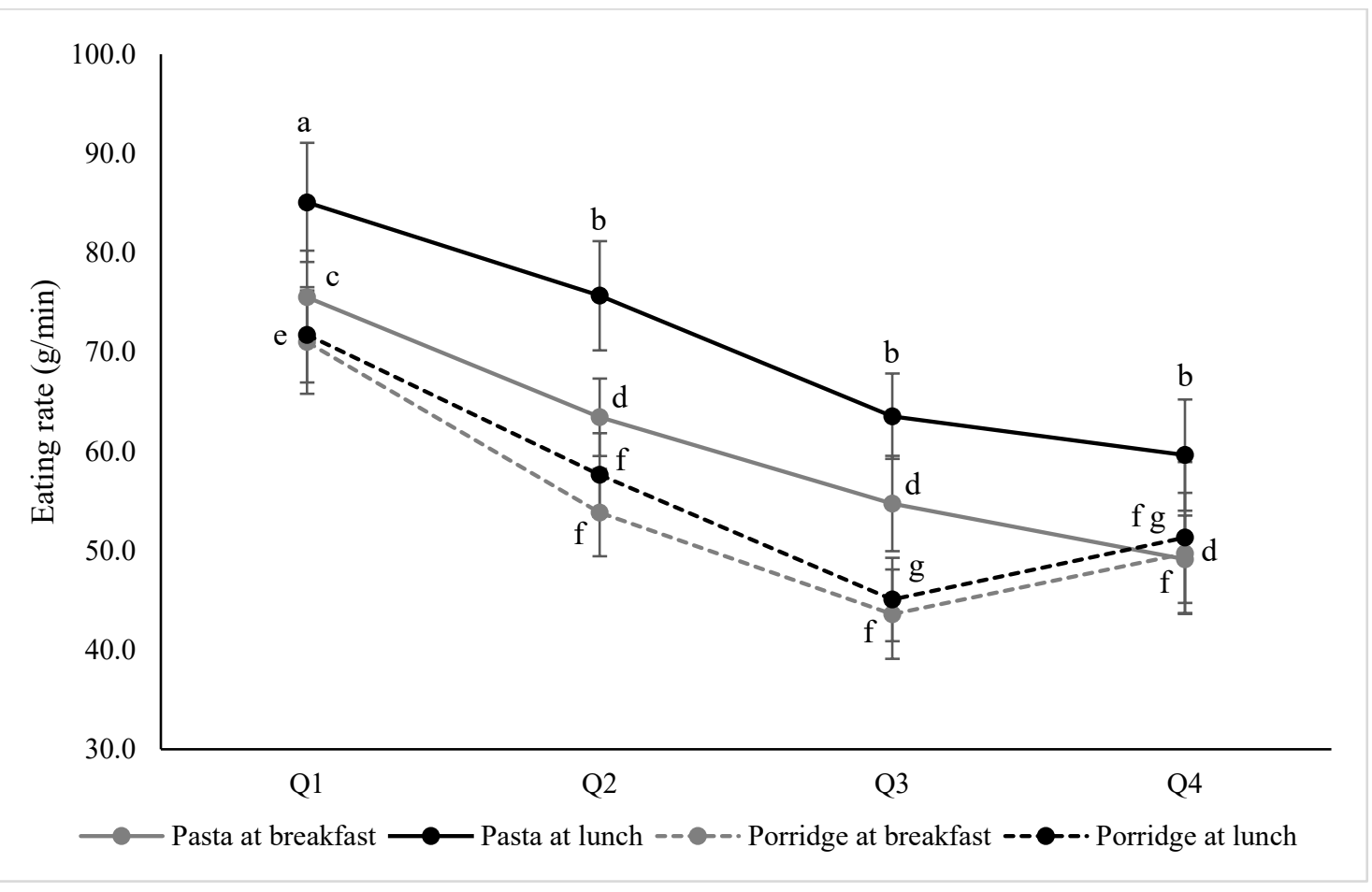

351 Figure 2. Mean $( \pm \mathrm{SEM})$ eating rate $(\mathrm{g} / \mathrm{min})$ per quartile for cheese and tomato pasta and porridge

352 with milk and honey at breakfast time and lunch time.

353 Letters a-d that are different indicate a significant difference between pasta mealtimes and 354 quartiles. 
355 Letters e-g that are different indicate a significant difference between porridge mealtimes and 356 quartiles.

358 For food intake, there was a significant effect of mealtime $(p<0.001)$ and a significant

359 mealtime-by-food-group interaction $(p<0.001)$, but no significant effect of food group $(p=$

360 0.25). Post hoc analysis indicated that food intake increased significantly from breakfast to lunch

361 for pasta $\left(t_{(38)}=-6.36, p<0.001, r=|0.72|\right)$ but did not increase significantly for porridge $\left(t_{(38)}=\right.$ -

$3620.78, p=0.88, r=|0.13|)($ see Figure 3).

363

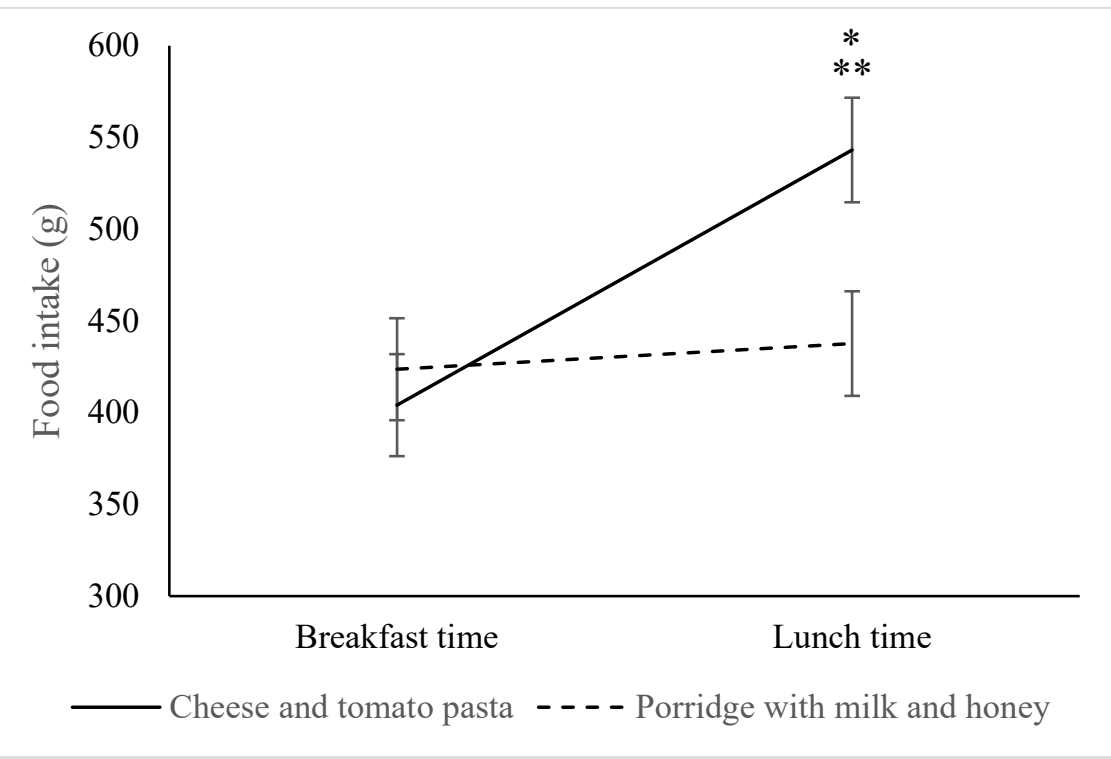

365 Figure 3. Mean $( \pm$ SEM) food intake $(\mathrm{g})$ for cheese and tomato pasta and porridge with milk and

366 honey at breakfast time and lunch time.

$367 *$ Food intake was higher at lunch time compared to breakfast time $(p<0.001)$.

** Food intake increased significantly from breakfast time to lunch time for the pasta group $(p<$

$3690.001)$ but did not differ significantly for the porridge group $(p=0.88)$. 
For eating duration, there were no significant effects of mealtime or food group, nor a

372 significant interaction $(p \geq 0.08)$, indicating no significant difference in eating duration between

373 mealtimes for the pasta group (breakfast time $=7.3 \pm 2.9 \mathrm{~min}$; lunch time $=8.2 \pm 2.4 \mathrm{~min}$ ) or

374 porridge group (breakfast time $=8.7 \pm 4.1 \mathrm{~min}$; lunch time $=8.8 \pm 4.3 \mathrm{~min}$ ).

For total mouthfuls per meal, a significant mealtime-by-food-group interaction $(p=0.02)$

376 with post hoc analysis indicated that more mouthfuls were taken by the pasta group at lunch time

$377(45.2 \pm 18.9)$ compared to breakfast time $\left(36.6 \pm 14.9 ; t_{(38)}=-4.91, p<0.001, r=|0.62|\right)$. There

378 was no significant change in total mouthfuls per meal for the porridge group at lunch time (38.3

$379 \pm 13.1)$ compared to breakfast time $\left(35.7 \pm 13.0 ; t_{(38)}=-1.51, p=0.28, r=|0.24|\right)$.

380 The significant mealtime effect for the average size of mouthfuls per meal $(p=0.048)$

381 indicated that slightly larger mouthfuls were taken at lunch time $(13.0 \pm 4.7 \mathrm{~g})$ compared to

382 breakfast time $(12.0 \pm 4.5 \mathrm{~g})$. The non-significant interaction $(p=0.097)$ indicated that there was

383 no difference between pasta or porridge groups in the inter-mealtime differences.

385 Table 3.

386 Main effects and interactions from the univariate analyses for eating rate, food intake, average

387 total mouthfuls, mouthful size and eating duration, and from the ANOVAs for postprandial

388 appetite, mealtime-specific appropriateness, mealtime-specific consumption frequency, desire to

389 eat and meal enjoyment.

\begin{tabular}{lllll}
\hline Variable & Factor & $F$ & $p$ & Effect size $(r)$ \\
\hline Eating rate & Mealtime & 13.63 & $<0.001$ & 0.39 \\
& Food group & 3.04 & 0.09 & 0.19 \\
& Mealtime x food group & 6.67 & 0.01 & 0.28 \\
& & & \\
Food intake & Mealtime & 29.34 & $<0.001$ & 0.53 \\
& Food group & 1.33 & 0.25 & 0.13 \\
& Mealtime x food group & 19.60 & $<0.001$ & 0.45 \\
\hline
\end{tabular}




\begin{tabular}{|c|c|c|c|c|}
\hline Variable & Factor & $F$ & $p$ & $\overline{\text { Effect size (r) }}$ \\
\hline Average total mouthfuls & $\begin{array}{l}\text { Mealtime } \\
\text { Food group } \\
\text { Mealtime } \mathrm{x} \text { food group }\end{array}$ & $\begin{array}{l}20.82 \\
1.57 \\
6.01\end{array}$ & $\begin{array}{l}<0.001 \\
0.22 \\
0.02\end{array}$ & $\begin{array}{l}0.46 \\
0.14 \\
0.27\end{array}$ \\
\hline Average mouthful size & $\begin{array}{l}\text { Mealtime } \\
\text { Food group } \\
\text { Mealtime } \mathrm{x} \text { food group }\end{array}$ & $\begin{array}{l}4.03 \\
0.001 \\
0.003\end{array}$ & $\begin{array}{l}0.048 \\
0.95 \\
0.97\end{array}$ & $\begin{array}{l}0.22 \\
0.01 \\
0.01\end{array}$ \\
\hline Average eating duration & $\begin{array}{l}\text { Mealtime } \\
\text { Food group } \\
\text { Mealtime } \mathrm{x} \text { food group }\end{array}$ & $\begin{array}{l}3.13 \\
2.01 \\
2.47\end{array}$ & $\begin{array}{l}0.08 \\
0.16 \\
0.12\end{array}$ & $\begin{array}{l}0.20 \\
0.16 \\
0.18\end{array}$ \\
\hline Postprandial appetite & $\begin{array}{l}\text { Mealtime } \\
\text { Food group } \\
\text { Mealtime } \mathrm{x} \text { food group }\end{array}$ & $\begin{array}{l}2.53 \\
0.20 \\
8.80\end{array}$ & $\begin{array}{l}0.12 \\
0.66 \\
0.004\end{array}$ & $\begin{array}{l}0.18 \\
0.05 \\
0.48\end{array}$ \\
\hline Appropriateness & $\begin{array}{l}\text { Mealtime } \\
\text { Food group } \\
\text { Mealtime x food group }\end{array}$ & $\begin{array}{l}<0.001 \\
2.87 \\
300.94\end{array}$ & $\begin{array}{l}0.99 \\
0.09 \\
<0.001\end{array}$ & $\begin{array}{l}<0.001 \\
0.19 \\
0.89\end{array}$ \\
\hline Consumption frequency & $\begin{array}{l}\text { Mealtime } \\
\text { Food group } \\
\text { Mealtime } \mathrm{x} \text { food group }\end{array}$ & $\begin{array}{l}4.23 \\
4.55 \\
58.03\end{array}$ & $\begin{array}{l}0.043 \\
0.036 \\
<0.001\end{array}$ & $\begin{array}{l}0.23 \\
0.24 \\
0.66\end{array}$ \\
\hline Desire to eat & $\begin{array}{l}\text { Mealtime } \\
\text { Food group } \\
\text { Mealtime } \mathrm{x} \text { food group }\end{array}$ & $\begin{array}{l}3.02 \\
2.87 \\
64.63\end{array}$ & $\begin{array}{l}0.09 \\
0.10 \\
<0.001\end{array}$ & $\begin{array}{l}0.20 \\
0.19 \\
0.68\end{array}$ \\
\hline Meal enjoyment & $\begin{array}{l}\text { Mealtime } \\
\text { Food group } \\
\text { Mealtime } \mathrm{x} \text { food group }\end{array}$ & $\begin{array}{l}0.25 \\
1.18 \\
66.61\end{array}$ & $\begin{array}{l}0.62 \\
0.28 \\
<0.001\end{array}$ & $\begin{array}{l}0.06 \\
0.12 \\
0.68\end{array}$ \\
\hline
\end{tabular}

Note: All variables are 'per meal'. All $\mathrm{df}_{\text {effect }}=1$, all $\mathrm{df}_{\text {error }}=76$.

\subsection{Postprandial appetite, mealtime-specific appropriateness, mealtime-specific previous}

See Table 3 for full ANOVA results. For the postprandial appetite scores, there was no

395 significant effect of mealtime or food group ( $p \geq 0.12)$. However, the significant mealtime-by-

396 food-group interaction $(p=0.004)$ and post hoc analysis indicated that participants were slightly

397 less full after they had eaten pasta at breakfast time $(13.9 \pm 11.4 \mathrm{~mm})$ compared to at lunch time 
$398\left(9.0 \pm 8.9 \mathrm{~mm}\right.$; mean difference between mealtimes $\left.=4.9 \mathrm{~mm} ; t_{(38)}=3.40, p=0.004, r=|0.48|\right)$.

399 There was no significant difference between postprandial appetite scores for porridge at

400 breakfast time $(11.8 \pm 11.1 \mathrm{~mm})$ and lunch time $(13.3 \pm 14.3 \mathrm{~mm}$; mean difference between

401 mealtimes $\left.=1.5 \mathrm{~mm} ; t_{(38)}=-0.93, p=0.72, r=|0.15|\right)$.

402

There were no significant main effects of mealtime or food group for mealtime-specific

403 appropriateness $(p \geq 0.09)$. However, the significant mealtime-by-food-group interaction $(p<$

404 0.001) with post hoc analysis indicated that pasta was rated as very appropriate for lunch time

$405(90.8 \pm 12.6 \mathrm{~mm})$ and not appropriate for breakfast time $\left(28.4 \pm 26.0 \mathrm{~mm} ; t_{(38)}=-12.26, p<\right.$

$4060.001, r=|0.89|)$, whereas porridge was rated as very appropriate for breakfast time $(96.3 \pm 10.1$

$407 \mathrm{~mm})$ and not appropriate for lunch time $\left(34.0 \pm 30.0 \mathrm{~mm} ; t_{(38)}=12.27, p<0.001, r=|0.89|\right)$.

408 A similar interaction was observed for the meal-specific consumption frequency data $(p<$

409 0.001). Post hoc analysis indicated that pasta was consumed more frequently at lunch time (63.5

$410 \pm 55.5$ times per year $)$ than at breakfast time $\left(2.8 \pm 11.1\right.$ times per year; $t_{(38)}=-7.27, p<0.001, r$

$411=|0.76|)$, and that porridge was consumed more frequently at breakfast time $(110.4 \pm 127.3$ times

412 per year $)$ than at lunch time $\left(4.8 \pm 10.0\right.$ times per year; $\left.t_{(38)}=5.24, p<0.001, r=|0.65|\right)$.

413 A similar pattern was observed for the desire to eat data. There were no significant main

414 effects of mealtime or food group $(p \geq 0.09)$. However, there was a significant mealtime-by-

415 food-group interaction $(p<0.001)$. Post hoc analysis indicated that pasta was desired more at

416 lunch time $(80.4 \pm 16.3 \mathrm{~mm})$ than at breakfast time $\left(63.5 \pm 21.6 \mathrm{~mm} ; t_{(38)}=-4.23, p<0.001, r=\right.$

$417|0.57|)$, and porridge was desired more at breakfast time $(78.4 \pm 19.8 \mathrm{~mm})$ than at lunch time

$418 \quad\left(52.3 \pm 24.7 \mathrm{~mm} ; t_{(38)}=7.33, p<0.001, r=|0.77|\right)$.

419 Finally, for postprandial meal enjoyment, there was no significant effect of mealtime or

420 food group $(p \geq 0.28)$ but, there was a significant interaction $(p<0.001)$. Post hoc analysis 
421 indicated that postprandial meal enjoyment scores were higher (i.e., the meal was more

422 enjoyable) in the congruous contexts compared to the incongruous contexts (pasta: $t_{(38)}=-5.44, p$

$423<0.001, r=|0.66|$, breakfast time $=58.2 \pm 22.5 \mathrm{~mm}$, lunch time $=83.1 \pm 19.6 \mathrm{~mm}$; porridge: $t_{(38)}$

$424=6.34, p<0.001, r=|0.72|$; breakfast time $=77.4 \pm 20.8 \mathrm{~mm}$, lunch time $=55.4 \pm 23.1 \mathrm{~mm})$.

\section{3.5. Correlations}

426 Table 4 provides full correlation data and statistics. Eating rate and food intake were

427 significantly and positively correlated in congruous contexts $(r=0.52, p<0.001)$, in

428 incongruous contexts $(r=0.39, p<0.001)$ and when analysing the difference in eating rate and

429 food intake, respectively, between congruous and incongruous contexts $(r=0.25, p=0.001)$.

430 That is, faster food consumption was associated with more food being consumed (and vice

431 versa), and the larger the change in eating rate between the congruous and incongruous context

432 the larger the change in food intake (and vice versa).

433 Differences in eating rate and food intake between contexts (change scores) were not

434 significantly associated with differences in mealtime-specific appropriateness $(p \geq 0.84)$,

435 mealtime-specific frequency $(p \geq 0.10)$, desire to eat $(p \geq 0.08)$, postprandial meal enjoyment $(p$

$436 \geq 0.35)$ or general consumption frequency $(p \geq 0.10)$. In incongruous contexts, eating rate was

437 only significantly associated with meal enjoyment $(r=0.21, p=0.007)$. In congruous contexts,

438 eating rate was only significantly associated with desire to eat $(r=0.19, p=0.01)$. In congruous

439 and incongruous contexts, food intake was additionally significantly associated with postprandial

440 meal enjoyment (congruous contexts: $r=0.20, p=0.01$; incongruous contexts: $r=0.17, p=$

4410.03 ) as well as with desire to eat (congruous contexts: $r=0.23 p=0.003$; incongruous contexts:

$442 \quad r=0.18, p=0.02)$. 

Mealtime-specific appropriateness was associated with desire to eat and meal enjoyment,

444 in both contexts, and for change scores $(p \leq 0.01)$. Mealtime-specific appropriateness was

445 associated with mealtime-specific previous consumption frequency only in incongruous contexts

$446 \quad(r=0.32, p<0.001)$.

447

448

449

450

451

452

453

454

455

456

457

458

459

460

461

462

463

464

465 
Table 4.

467 Associations between eating rate, food intake, mealtime-specific previous consumption frequency, mealtime-specific appropriateness,

468 desire to eat, postprandial meal enjoyment and general consumption frequency.

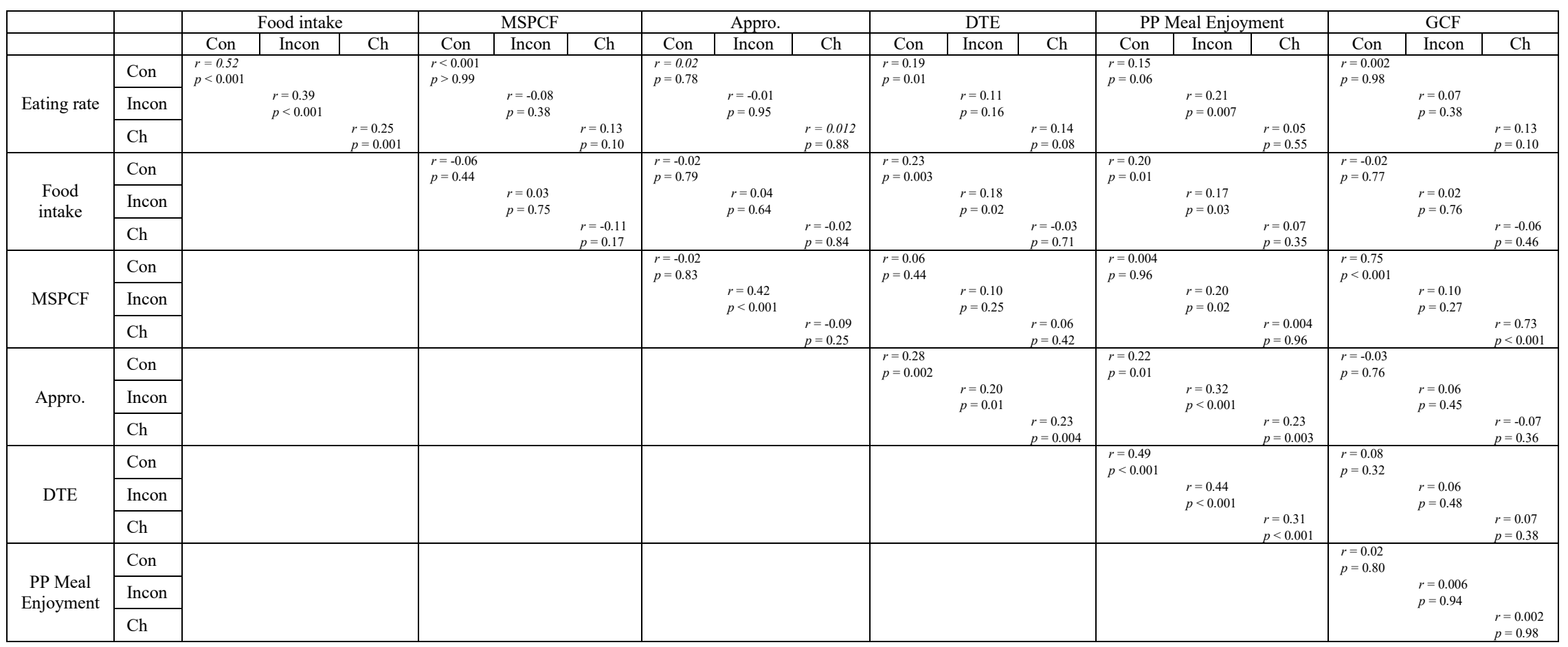

470 Notes: $\mathrm{MSPCF}=$ Mealtime-specific previous consumption frequency. Appro. $=$ Mealtime-specific appropriateness. DTE $=$ Desire to eat. PP Meal

471 Enjoyment $=$ Postprandial meal enjoyment. GCF $=$ General consumption frequency. Con $=$ Congruous contexts. Incon $=$ Incongruous contexts. $\mathrm{Ch}=$

472 change (square of the difference) between congruous and incongruous contexts. 


\subsection{Discussion}

This study explored whether eating rate and food intake are reduced when food is consumed at incongruous (vs congruous) mealtimes. Our main finding was that eating rate was

476 slower and less food was consumed in only one of the incongruous contexts (pasta at breakfast

477 time). Comparatively, eating rate and food intake were similar between contexts for porridge. For

478 the pasta group, average total mouthfuls increased from breakfast time to lunch time, with no 479 significant change or difference in eating duration or average mouthful size for either food group.

480 This suggests that the increase in eating rate related to an increase in mouthfuls per minute rather 481 than mouthful size.

Our results revealed that eating rate and food intake were correlated, corroborating

483 previous findings (Robinson et al., 2014). Therefore, it is likely that changes in eating rate and/or

484 food intake are driving the response from the other and referring to previous studies in this area

485 allows us to further dissect this interaction. A study from our laboratory investigating pre-meal

486 decisions revealed that both smaller ideal portions, and portions selected to stave off hunger were

487 chosen when foods were presented in incongruous contexts (e.g., lunch foods at breakfast time)

488 compared to congruous contexts (e.g., lunch foods at lunch time) (McLeod et al., 2020).

489 Research has also shown that smaller portions engender slower eating rates (Almiron-Roig et al.,

490 2015; Wilkinson et al., 2016). This suggests that participants in our current study may have made

491 pre-meal decisions (with or without conscious thought) to consume less food in an unusual

492 context compared to in a usual context and that these pre-meal decisions to consume less food

493 may have led to a slower eating rate. That said, another possibility is that food may have been

494 consumed slower in unusual contexts as more conscious thoughts about the food's characteristics

495 (e.g., flavour, palatability, fillingness) and about when to stop eating are considered during the 
meal. Conversely, in usual contexts, these food-related thoughts and decisions may be more

497 effortless because the process of food selection and consumption has become somewhat more

498 practiced, leading to a quicker eating rate. However, the eating rate data per quartile in the

499 current study does not support this latter hypothesis as eating rate decreased sequentially and

500 similarly between quartiles for both porridge and pasta in both congruous and incongruous

501 contexts. If thoughts and decisions about the food were more considered in unusual contexts, we

502 would perhaps expect to see a slower eating rate in the first quartile as participants become

503 accustomed to consuming the food in a novel context. As this was not the case, we expect that

504 pre-meal decisions to consume a smaller portion led to a slower eating rate.

These results build on previous findings to suggest that there may be clinical application

506 to consuming a food at unusual mealtimes for healthy weight management. That is, in unusual

507 food-to-mealtime contexts, smaller portions may be selected as an ideal portion, expectations of

508 satiety may be satisfied with less food (McLeod et al., 2020), and food may be eaten slower, with

509 less food consumed. However, for the manipulation of food-to-mealtime congruency to be a

510 beneficial strategy for reducing food intake, postprandial hunger should be abated to the same

511 extent in both usual and unusual contexts. Although our findings showed that postprandial

512 appetite was greater when participants consumed pasta at breakfast time compared to at lunch

513 time, the difference between the scores was small. That is, when also considering the

514 postprandial appetite scores for porridge with milk and honey (which had no significant

515 difference between contexts), the range of average postprandial appetite scores was from $9.0 \mathrm{~mm}$

516 to $13.9 \mathrm{~mm}$, a difference of $<5 \mathrm{~mm}$ on a 100-mm VAS. Notwithstanding this small but

517 significant difference, future work should explore whether energy compensation occurs later in

518 the day after consuming a food at an incongruous mealtime. Research should also investigate 
519 how long this strategy might be effective before an incongruous food-to-mealtime association is

520 normalised. These considerations are important to understand as introducing foods at unusual

521 mealtimes may increase dietary variety which has been shown to compromise control of food

522 intake (Hardman, Ferriday, Kyle, Rogers, \& Brunstrom, 2015). Thus, until further research is

523 undertaken, increasing the variety of food options that are appropriate for an individual to

524 consume at a particular mealtime should be facilitated with caution.

These results may also have positive implications for vulnerable populations (such as the

526 elderly or infirm) who need to increase food intake. That is, in congruous food-to-mealtime

527 contexts, larger portions (with lower expected satiety) may be selected, food may be eaten

528 quicker and more food may be consumed. Therefore, future research should explicitly investigate

529 whether foods marketed as mealtime-specific are more likely to be selected for consumption and

530 are associated with higher food intake. If research confirmed this hypothesis, and this strategy

531 was implemented with food products of nutritionally-beneficial composition (e.g., high in energy

532 density) this approach would add to implicit nudge strategies designed to improve the nutrition

533 of vulnerable populations (Lakerveld et al., 2018; Thaler \& Sunstein, 2009).

534 We aimed to confirm that our manipulation of food-to-mealtime congruency was

535 achieved (i.e., porridge was considered a breakfast food only, and pasta was considered a lunch

536 food only) by observing high ratings of appropriateness, mealtime-specific previous

537 consumption frequency, desire to eat and post-meal enjoyment in congruous contexts, and

538 comparatively lower ratings in incongruous contexts. To this extent, our manipulation was

539 successful as all measures differed between contexts, as expected. However, notwithstanding

540 these results, the eating rate and food intake patterns between congruous and incongruous

541 contexts differed for the pasta and porridge groups. This pattern of results reflects the findings 
542 from our previous work (McLeod et al., 2020). With this in mind, the exploratory analysis in the

543 current study aimed to reveal the correspondence between eating rate, food intake and the

544 subjective measures in order to better understand the mechanism underlying the influence of

545 food-to-mealtime congruency. Specifically, our previous work implicated mealtime-specific

546 previous consumption frequency and mealtime-specific appropriateness as potential influential

547 factors. However, our analysis found no consistent association between eating rate, food intake

548 and the subjective measures in this study. Therefore, other factors and mechanisms may help to

549 explain these changes and we provide three speculative suggestions. Firstly, a measure of disgust

550 might better capture the experience of eating foods in different contexts, e.g., eating pasta at

551 breakfast time may be more disgusting to consumers than eating porridge at lunch time.

552 Secondly, differences in portion selection, eating rate and consumption between contexts might

553 be flavour-related, e.g., different for sweet vs savoury foods. Thirdly, it is possible that the

554 difference in the homogeneity of our food choices played a role in our results; that is, porridge

555 with milk and honey is more homogenous in texture than cheese and tomato pasta. Chewing

556 might be a more arduous task in the morning and pasta requires slightly more chewing than

557 porridge. A thick, savoury soup, for example, might be used as a comparison to porridge in

558 subsequent work.

559 This study had a few limitations to highlight. Firstly, two participants stated at the debrief

560 that they were aware that food intake was being measured. This may have changed the amount of

561 food they consumed. Similarly, the use of an alarm to indicate when participants had consumed

562 four fifths of their initial portion may have alerted participants to the fact that their eating was

563 being observed. This may have affected their willingness to eat more of the food (particularly

564 when the food was presented at an unusual mealtime). That said, previous work showed that 
565 participant awareness of food intake being measured did not influence food intake with a main

566 pasta dish (whereas it did influence intake for snack foods) (Thomas, Dourish, \& Higgs, 2015).

567 Furthermore, only two of 78 participants reported this awareness presenting a low risk of a

568 confounded dataset. Secondly, the measures of mealtime-specific previous consumption

569 frequency and appropriateness were assessed before participants consumed their food. This pre-

570 meal assessment may have primed participants to more-consciously consider the food-to-

571 mealtime association which may have impacted eating rate and food intake. Future work should

572 assess mealtime-specific previous consumption frequency and appropriateness after the eating

573 session.

574 In conclusion, this study found that eating rate and food intake are reduced when a food

575 is consumed at an unusual mealtime. Previous research on the influence of the food-to-mealtime

576 context on pre-meal portion selections leads us to believe that pre-meal decisions to consume

577 less food, when it is presented in an unusual context, subsequently influences eating rate and

578 food intake. This finding has a potential clinical application as a weight management strategy to

579 decrease food intake. However, future research should explore the longer-term effects of the

580 acute reduction in food intake in incongruous contexts (such as whether energy compensation

581 occurs at a later meal) and how long this strategy may be beneficial. This finding also has a

582 potential clinical application to increase food intake as, conversely, larger portions are consumed

583 when foods are mealtime-congruous. Therefore, future work should investigate whether

584 marketing foods as mealtime-specific could be a successful implicit nudge strategy to increase

585 food intake and improve the nutrition of vulnerable populations.

\section{Conflict of interest}


The authors declare no conflict of interest.

\section{Author contributions}

591 Conceptualisation, writing (reviewing and editing) and methodology: C.J.M., L.J.J., and G.L.W.;

592 investigation, formal analysis, computer programming and writing (original draft): C.J.M..

\section{Funding}

595 This research did not receive any specific grant from funding agencies in the public, commercial, 596 or not-for-profit sectors.

\section{References}

599 Almiron-Roig, E., Tsiountsioura, M., Lewis, H. B., Wu, J., Solis-Trapala, I., \& Jebb, S. A.

600 (2015). Large portion sizes increase bite size and eating rate in overweight women.

$601 \quad$ Physiology and Behavior, 139, 297-302. https://doi.org/10.1016/j.physbeh.2014.11.041

602 Andrade, A. M., Kresge, D. L., Teixeira, P. J., Baptista, F., \& Melanson, K. J. (2012). Does eating 603 slowly influence appetite and energy intake when water intake is controlled? International 604 Journal of Behavioral Nutrition and Physical Activity, 9, 135. https://doi.org/10.1186/1479$605 \quad 5868-9-135$

606 Blass, E. M., Anderson, D. R., Kirkorian, H. L., Pempek, T. A., Price, I., \& Koleini, M. F. (2006).

607 On the road to obesity: Television viewing increases intake of high-density foods.

608 Physiology and Behavior, 88(4-5), 597-604. https://doi.org/10.1016/j.physbeh.2006.05.035

609 Bobroff, E. M., \& Kissileff, H. R. (1986). Effects of changes in palatability on food intake and 610 the cumulative food intake curve in man. Appetite, 7(1), 85-96. 

https://doi.org/https://doi.org/10.1016/S0195-6663(86)80044-7

612 Bolhuis, D. P., Lakemond, C. M. M., de Wijk, R. A., Luning, P. A., \& de Graaf, C. (2013).

613 Consumption with Large Sip Sizes Increases Food Intake and Leads to Underestimation of 614 the Amount Consumed. PLoS ONE, 8(1), e53288.

615 https://doi.org/10.1371/journal.pone.0053288

616 Brunstrom, J. M. (2014). Mind over platter: Pre-meal planning and the control of meal size in 617 humans. International Journal of Obesity, 38, S9-S12. https://doi.org/10.1038/ijo.2014.83

618 Brunstrom, J. M., \& Rogers, P. J. (2009). How many calories are on our plate? Expected fullness, 619 not liking, determines meal-size selection. Obesity, 17(10), 1884-1890.

620 https://doi.org/10.1038/oby.2009.201

621 Clayton, D. J., \& James, L. J. (2016). The effect of breakfast on appetite regulation, energy

622 balance and exercise performance. Proceedings of the Nutrition Society, 75(3), 319-327.

$623 \quad$ https://doi.org/10.1017/S0029665115004243

624 Cohen, J. (1992). A power primer. Psychological Bulletin, 112(1), 115-159.

$625 \quad$ https://doi.org/10.1037/0033-2909.112.1.155

626 de Castro, J. M. (1990). Social facilitation of duration and size but not rate of the spontaneous 627 meal intake of humans. Physiology and Behavior, 47(6), 1129-1135.

628 https://doi.org/10.1016/0031-9384(90)90363-9

629 de Castro, J. M. (1994). Family and friends produce greater social facilitation of food intake than 630 other companions. Physiology and Behavior, 56(3), 445-455. https://doi.org/10.1016/0031$6319384(94) 90286-0$

632 de Castro, J. M. (1995). Social facilitation of food intake in humans. Appetite, 24(3), 260.

633 https://doi.org/10.1016/S0195-6663(95)99835-7 
634 Fay, S. H., Ferriday, D., Hinton, E. C., Shakeshaft, N. G., Rogers, P. J., \& Brunstrom, J. M.

635

636

637

638

639

640

641

642

643

644

645

646

647

648

649

650

651

652

653

654

655

656 (2011). What determines real-world meal size? Evidence for pre-meal planning. Appetite, 56(2), 284-289. https://doi.org/10.1016/j.appet.2011.01.006

Ferriday, D., Bosworth, M. L., Godinot, N., Martin, N., Forde, C. G., Van Den Heuvel, E., ... Brunstrom, J. M. (2016). Variation in the oral processing of everyday meals is associated with fullness and meal size; A potential nudge to reduce energy intake? Nutrients, $8(5), 1-$ 28. https://doi.org/10.3390/nu8050315

Forde, C. G., van Kuijk, N., Thaler, T., de Graaf, C., \& Martin, N. (2013). Texture and savoury taste influences on food intake in a realistic hot lunch time meal. Appetite, 60(1), 180-186. https://doi.org/10.1016/j.appet.2012.10.002

Hardman, C. A., Ferriday, D., Kyle, L., Rogers, P. J., \& Brunstrom, J. M. (2015). So many brands and varieties to choose from: Does this compromise the control of food intake in humans? PLoS ONE, 10(4), 1-17. https://doi.org/10.1371/journal.pone.0125869

Hermans, R. C. J., Hermsen, S., Robinson, E., Higgs, S., Mars, M., \& Frost, J. H. (2017). The effect of real-time vibrotactile feedback delivered through an augmented fork on eating rate, satiation, and food intake. Appetite, 113, 7-13. https://doi.org/10.1016/j.appet.2017.02.014

Hogenkamp, P. S., \& Schiöth, H. B. (2013). Effect of oral processing behaviour on food intake and satiety. Trends in Food Science and Technology, 34(1), 67-75. https://doi.org/10.1016/j.tifs.2013.08.010

James, L. J., Maher, T., Biddle, J., \& Broom, D. R. (2016). Spoon size effects energy intake at an ad-libitum porridge breakfast. Appetite, 101, 232. https://doi.org/http://dx.doi.org/10.1016/j.appet.2016.02.114

Lakerveld, J., Mackenbach, J. D., De Boer, F., Brandhorst, B., Broerse, J. E. W., De Bruijn, G. J., 

... Beulens, J. W. J. (2018). Improving cardiometabolic health through nudging dietary behaviours and physical activity in low SES adults: Design of the Supreme Nudge project. BMC Public Health, 18, 899. https://doi.org/10.1186/s12889-018-5839-1

660 Leong, S. L., Madden, C., Gray, A., Waters, D., \& Horwath, C. (2011). Faster Self-Reported Speed of Eating Is Related to Higher Body Mass Index in a Nationwide Survey of MiddleAged Women. Journal of the American Dietetic Association, 111(8), 1192-1197. https://doi.org/10.1016/j.jada.2011.05.012

Llewellyn, C. H., Van Jaarsveld, C. H. M., Boniface, D., Carnell, S., \& Wardle, J. (2008). Eating

McLeod, C. J., James, L. J., Brunstrom, J. M., \& Witcomb, G. L. (2020). The influence of expected satiety on portion size selection is reduced when food is presented in an 'unusual' meal context. Appetite, 147, 104550. https://doi.org/10.1016/j.appet.2019.104550

McCrickerd, K., \& Forde, C. G. (2016). Sensory influences on food intake control: Moving beyond palatability. Obesity Reviews, 17(1), 18-29. https://doi.org/10.1111/obr.12340 rate is a heritable phenotype related to weight in children. American Journal of Clinical Nutrition, 88(6), 1560-1566. https://doi.org/10.3945/ajen.2008.26175

Monsivais, P., Perrigue, M. M., \& Drewnowski, A. (2007). Sugars and satiety: Does the type of sweetener make a difference? American Journal of Clinical Nutrition, 86(1), 116-123. https://doi.org/10.1093/ajcn/86.1.116

Perrigue, M. M., Drewnowski, A., Wang, C.-Y., \& Neuhouser, M. L. (2015). Higher Eating Frequency Does Not Decrease Appetite in Healthy Adults. The Journal of Nutrition, 146(1), 59-64. https://doi.org/10.3945/jn.115.216978

Perrigue, M. M., Monsivais, P., \& Drewnowski, A. (2009). Added Soluble Fiber Enhances the 

Association, 109(11), 1862-1868. https://doi.org/10.1016/j.jada.2009.08.018

Robinson, E., Almiron-roig, E., Rutters, F., de Graaf, C., Forde, C. G., Smith, C. T., ... Jebb, S. A. (2014). A systematic review and meta-analysis examining the effect of eating rate on energy intake and hunger. American Journal of Clinical Nutrition, 100(1), 123-151. https://doi.org/10.3945/ajcn.113.081745

Rosenthal, R. (1994). Parametric measures of effect size. (H. Cooper \& L. V. Hedges, Eds.), The handbook of research synthesis. Russell Sage Foundation.

Ryan, D. H., Parkin, C. G., Longley, W., Dixon, J., Apovian, C., \& Bode, B. (2018). Efficacy and safety of an oral device to reduce food intake and promote weight loss. Obesity Science \& Practice, 4(1), 52-61. https://doi.org/10.1002/osp4.139

Schubert, M. M., Irwin, C., Seay, R. F., Clarke, H. E., Allegro, D., \& Desbrow, B. (2017). Caffeine, coffee, and appetite control: a review. International Journal of Food Sciences and Nutrition, 68(8), 901-912. https://doi.org/10.1080/09637486.2017.1320537

Scisco, J. L., Muth, E. R., Dong, Y., \& Hoover, A. W. (2011). Slowing Bite-Rate Reduces Energy Intake: An Application of the Bite Counter Device. Journal of the American Dietetic Association, 111(8), 1231-1235. https://doi.org/10.1016/j.jada.2011.05.005

Stunkard, A. J., \& Messick, S. (1985). The three-factor eating questionnaire to measure dietary restraint, disinhibition and hunger. Journal of Psychosomatic Research, 29(1), 71-83. https://doi.org/10.1016/0022-3999(85)90010-8

Thaler, R. H., \& Sunstein, C. R. (2009). Nudge - Improving Decisions about Health, Wealth, and Happiness (1st ed.). Penguin Group. https://doi.org/10.1017/CBO9781107415324.004

Thomas, J. M., Dourish, C. T., \& Higgs, S. (2015). Effects of awareness that food intake is being measured by a universal eating monitor on the consumption of a pasta lunch and a cookie 
snack in healthy female volunteers. Appetite, 92, 247-251.

704 https://doi.org/10.1016/j.appet.2015.05.034

705 Westerterp-Plantenga, M. S. (2000). Eating behavior in humans, characterized by cumulative 706 food intake curves - A review. Neuroscience and Biobehavioral Reviews, 24(2), 239-248. https://doi.org/10.1016/S0149-7634(99)00077-9

708 Wilkinson, L. L., Ferriday, D., Bosworth, M. L., Godinot, N., Martin, N., Rogers, P. J., \& 709 Brunstrom, J. M. (2016). Keeping Pace with Your Eating: Visual Feedback Affects Eating 710 Rate in Humans. PLoS ONE, 11(2), 1-13. https://doi.org/10.1371/journal.pone.0147603

711 Wilkinson, L. L., Hinton, E. C., Fay, S. H., Ferriday, D., Rogers, P. J., \& Brunstrom, J. M.

712 (2012). Computer-based assessments of expected satiety predict behavioural measures of 713 portion-size selection and food intake. Appetite, 59(3), 933-938.

714 https://doi.org/10.1016/j.appet.2012.09.007

715 Yeomans, M. R., Chambers, L., \& Mccrickerd, K. (2018). Expectations About Satiety and Thirst 716 Are Modified by Acute Motivational State. Frontiers in Psychology, 9(December), 1-10. 717 https://doi.org/10.3389/fpsyg.2018.02559 